\title{
Analysis of Mast Management Distribution and Telecommunication Service Using Geospatial Technique
}

\author{
Dr. Omogunloye O.G. ${ }^{1}$, Surv. Qaadri J. A. ${ }^{2}$, Mrs. Omogunloye H.B ${ }^{3}$. and \\ Surv. Oladiboye O.E \\ ${ }^{I}$ Dept. of Surveying and Geoinformatics, University of Lagos, Lagos \\ ${ }^{2}$ Dept. of Surveying and Geoinformatics, Federal School of Surveying, Oyo, Oyo State \\ ${ }^{3}$ Dept. of English Language, University of Lagos, Lagos \\ ${ }^{4}$ Dept. of Surveying and Geoinformatics, Yaba Tech, Lagos
}

\begin{abstract}
Information management has become a very important topic in recent times and technological advancement depends more and more on the amount of information that is available in real time. As the popular saying goes information is power. This is why investment in the information networking of an economy cannot be over flogged. Great nations of today are characterized by the amount of information they harness and how well and efficient this information is being dispersed to its citizens.

GIS (Geographic Information System) is of great importance in accomplishing modern day task of information management. This project is focused on the direct application GIS is proffering solutions to telecommunications masts distribution, the spread and their locations. For this study, two major telecoms companies in Lagos were chosen for consideration and analysis in other to appreciate the lapses and the short comings of the present spread and the need for a spatial adjustment. Also given the ongoing Federal Government proposed policy on mast stations networking by all telecom companies, we shall achieve maximum output, reduced cost of service and increase in the efficiency of the telecoms companies to all the customers.

Geographic information System (GIS) as a tool enables telecommunication professionals to integrate maps and information for better decision making, from planning and maintenance of infrastructure to administering of mobile telephone coverage, managing existing customers and finding of new ones. In all these GIS Users rely on location based data to proffer solutions.

The methodology employed for this project is data acquisition, data storage, data manipulation and data presentation. Analyses of the results obtained shows the spatial distribution of the masts around Lagos state and highlights the different logical paths the GIS can be queried to achieve the required results. This study has provided a Geospatial analysis of Mast Management distribution and Telecommunication Service in Lagos State.
\end{abstract}

Keywords: Mast, Distribution, Zoom Mobile and MTN, Map, Query.

\subsection{What is Telecommunications?}

\section{Introduction}

Telecommunications has been defined as a technology concerned with communicating from a distance (TARMO, 2003). Figure 1.1 shows one possible view of the different sections of telecommunications. It includes mechanical communication and electrical communication because telecommunications has evolved from a mechanical to an electrical form using increasingly more sophisticated electrical systems. This is why many authorities such as the national post, telegraph, and telephone (PTT) companies are involved in telecommunications using both forms.

Our main concern here is electrical and bidirectional communication, as shown in the upper part of Figure 1.1. The share of mechanical telecommunications such as conventional mail and press is expected to decrease, whereas electrical, especially bidirectional, communication will increase and take the major share of telecommunications in the future. Hence, major press corporations are interested in electrical telecommunications as a business opportunity.

\subsection{Significance of Telecommunications}

Many different telecommunications networks have been interconnected into a continuously changing and extremely complicated global system. We look at telecommunications from different points of view in order to understand what a complicated system we are dealing with and how dependent we are on it. Figure 1.1 showed a display of Telecommunications Engineering Network, (Burroughs, 1986; Petkovic, 2002; and Tarmo, 2003). 
Telecommunications networks make up the most complicated network in the world. Let us think only of the telephone network, which includes more than 2 billion fixed and cellular telephones with universal access. When any of these telephones requests a call, the telephone network is able to establish a connection to any other telephone in the world. In addition, many other networks are interconnected with the telephone network. This gives us a view of the complexity of the global telecommunications network-no other system in the world exceeds the complexity of telecommunications networks.

Telecommunications services have an essential impact on the development of a community. If we look at the telephone density of a country, we can estimate its level of technical and economical development. In the developing countries, prior to the introduction of Global System for Mobile (GSM), the fixed telephone density (tele - density) is fewer than 10 telephones per 1,000 inhabitants; while in developed countries North America and Europe for instance, there are around 500 to 600 fixed telephones per 1,000 inhabitants (TARMO,2003). The economic development of developing countries depends on (in addition to many other things) the availability of efficient telecommunications services.

The operations of a modern community are highly dependent on telecommunications. We can hardly imagine our working environment without telecommunications services. The local area network (LAN) for instance, to which our computer is connected is interconnected with the LANs of other sites throughout our Company. This is mandatory so that the various departments can work together efficiently. We communicate daily with people in other organizations with the help of electronic mail(internet), telephones, facsimile, and mobile telephones. Governmental organizations that provide public services are as dependent on telecommunications services as are private organizations, (Chan, et al, 1997; Godin, 2001; and. Gunnar, 1998).

Telecommunications plays an essential role on many areas of everyday living. Everyday life is dependent on telecommunications. Each of us uses telecommunications services and services that rely on telecommunications daily. Here are some examples of services that depend on telecommunications:

- Banking, automatic teller machines, tele - banking;

- Aviation, booking of tickets;

- Sales, wholesale and order handling;

- Credit card payments at gasoline stations;

- Booking of hotel rooms by travel agencies;

- Material purchasing by industry;

- Government operations, such as taxation.

In the telecommunications world, a GIS is ideally suited for network planning and development. The ability to layer information onto the earth's surface, complete with attribute data, allows engineers the unique ability to model and assess a network from the office. This saves valuable time and reduces the number of trips, if any, that the engineer must make to the field. Furthermore, the powerful automation capabilities offered by a GIS increase the speed and accuracy of the network design process and can help reduce, and even eliminate, the downstream impacts of design-phase errors on cost and schedule during the network deployment phase. Rulebased features found in a GIS can also offer network designers the ability to produce better products, optimized for cost, shortest routing distances, or other user-defined metrics. The skill level and design time involved in hand-producing comparable designs would be significantly higher.

The GIS is an essential tool in the telecommunication industry. Most wireless network engineers are familiar with the GIS as the backbone of many wireless design tools already in use. By incorporating digital elevation models (DEMs), land clutter (LC) data, and building elevation models, wireless engineers are able to assess radio coverage before the network is built, identify areas that require enhanced capacity or coverage, and plan for trends in network and application performance. However, a GIS can be used even before engineers set pen to paper. For marketing efforts, population data can be added to enable network traffic and resource utilization calculations. Aggregating block-level population data into rough coverage rings yields statistics on expected network complexity and required capital expenditures before network design even begins. Such numbers can be extremely effective when used in business development proposals because they originate from real-world models.

A GIS can further be used in business development efforts at both the strategic and operational scales to determine where coverage expansion should be directed and how the ensuing network should be deployed. Demographic data can be leveraged to identify population centers and areas of high income. A demographic approach removes the need for strategic planners to "throw darts at the map."Income estimates further allow engineers to target geographic areas with high disposable income that will be most likely to subscribe to new services. The benefits of this approach are obvious and are further validated by its increasing use in diverse business lines. Simply by picking up a business atlas or doing Internet research, planners can identify underserved markets and provide opportunities for revenue generation. Using a GIS allows the engineer to add existing and competitive coverage to the map to improve the context of the data provided, (Demers, 1997; Galati, 2006; and Jones, 2005). 
The purpose of the study is to show how geographic information system (GIS) can be used to enhance the productivity of the GSM telecommunication industry especially in the area of network planning and management, decision and operations support, marketing and sales, customer care and in the provision of value added services.

\subsection{Study Area}

The study area is Lagos State of Nigeria. Lagos State is an administrative region of Nigeria, located in the southwestern part of the country. The smallest of Nigeria's states, Lagos State is the second most populous state after Kano State, and arguably the most economically important state of the country, containing Lagos, the nation's largest urban area.

Lagos State was created on May 27, 1967. With the formal relocation of the seat of the Federal Government to Abuja on 12 December 1991, Lagos ceased to be Nigeria's political capital. Nevertheless, Lagos remains the center of commerce and industry for the country.

Lagos State is the smallest state in Nigeria, yet it has the highest population. According to the 1991 national census, Lagos State had a population of $5,725,116$ out of a national total of $88,992,220$. However, the preliminary results of the 2006 census show that Lagos State has now 9,013,534 inhabitants out of a national total of $140,003,542$. This is nonetheless less than what was anticipated.

\subsection{Aims and Objectives of the Project}

The aim of this project is to provide a Decision Support System using GIS as a tool in the decisionmaking process to enhance the productivity of the telecommunication industry especially in the area of network planning and management, decision and operations support, marketing and sales customer care and in the provision of value added services, using Zoom Mobile formerly known as Reliance Telecommunication (Reltel) and MTN Telecommunication Limited as a case study.

The objectives of this project work are

- To create base maps for the Base station transceiver of the telecommunication provider within the area of study, demographic maps of the area, digital elevation model (DEM) of the area and road networks within the area of study.

- To create attribute database for the features mapped.

- To perform spatial analysis and information generation from the database created.

\subsection{Scope of the Study}

The scope of this study involves;

- Acquisition and use of recently acquired spatially referenced and remotely sensed data such as satellite imagery, topographic maps and administrative and road maps of the area of study.

- Digitizing of the maps and satellite imagery acquired.

- Creation of the attribute tables making up the database.

- Generation of spatial queries to produce desired result.

\subsection{Statement of Problem}

Solving the many business problems of a telecommunications company requires a good understanding of where your customers and facilities exist today and where they will be tomorrow. In an industry that changes so rapidly, the capability to find, manage, and analyze data quickly and effectively makes a strategic difference. In the traditional technique, the process of tracking the availability of network interconnectivity and accuracy of Base Station Transceiver Subsystem transmissions is too time consuming which often results in significant delays in providing services to customers and operations such as repairs and maintenance.

Geographic information system (GIS) as a tool will enable telecommunication professionals to integrate maps and information to make better decisions. From planning and maintaining network infrastructure to administering mobile telephone coverage, managing existing customers, and finding new ones, GIS users rely on location-based data to find the answers. GIS allows carriers to keep track of customer mobility and trends in the staggering bandwidth requirements driven by entertainment and Internet services. Viewing information on a map makes it quicker and more intuitive than relying on spreadsheets and other tabular data.

With the consideration of the benefits, it is justifiable to advise the disengagement of the manual method and engage a computer based geographic information system approach in handling utility service provision because the availability of GIS provides solutions to decision makers across the organization with immediate answers to complex business questions and its flexibility allows for all departments to share this information which encourages the unity of purpose in a company thereby improving many aspects of its operations and keeping their present and future customers satisfied which is the ultimate goal of any servicing company. 


\section{Methodology}

\subsection{Reconnaissance}

Reconnaissance (also called Recce) is the first step in the execution of any project. It is important to perform a reconnaissance operation so as to have an insight into the work to be done and to aid accurate decision making during execution of the project. Therefore reconnaissance can be termed the preparatory stage for project execution and it involves the assembling, examination, and collection or over viewing of the project site and/or logistics for successful execution as it enables one to obtain the picture of the whole area so as to work economically in terms of time, energy and finances.

For the purpose of this project, the reconnaissance carried out can be divided into Office recce and Field recce on the study area, (Egyedi, 2001; and Esri, 2006)..

\subsubsection{Office Reconnaissance}

Office reconnaissance which was carried out involved the following activities:

1. Selection of Hardware,

2. Selection of Software,

3. Selection of Equipments,

4. Collating existing data,

5. Determining the coordinate system for the data to be used.

\subsubsection{Hardware}

Hardware was used to acquire, store, process, manipulate, analyse the digital data. The hardware components used is a laptop computer with the following configuration:

1. Intel Core 2 Duo

2. $1.6 \mathrm{GigaHz}$,

3. 160 Gigabyte hard disk (memory space),

4. 3 Gigabyte of RAM,

5. 512 Megabyte of Nvidia graphics card,

6. Hewlett Packard Desk Jet 9800 A3 Printer

7. Garmin road tracker GPS

\subsubsection{Software}

The software used to produce the GIS and carry out manipulation operations. The project was carried using the following software:

1. Windows XP Operating System

2. Franson Coordinate Converter

3. Microsoft Office 2007

4. Autodesk 3ds Max 2008

5. ESRI ArcGIS 9.2 Desktop

6. Google Earth Plus 5.0

7. Surfer 8.0

8. Autodesk AutoCAD 2006

\subsubsection{Field Reconnaissance}

We went to the field to determine the instrumentation to be used and how best we can optimize our time, Instrument Etc.

\subsection{Procedure of Execution}

The methodology adopted for this project involves all stages of executing a GIS project and they are:

1. Data Acquisition

2. Data Storage

3. Data Processing (Manipulation)

4. Information Presentation

\subsubsection{Data Acquisition}

The data used for the project can be divided into two parts (types) of data which

- Existing data

- And acquired data 


\subsubsection{Existing Data} data include;

This was gotten from departmental archives and from the database of well known GIS repositories, these

- Administrative map of Lagos including the population distribution as at the 2005 national population census

- Lagos state detailed street maps

- Mast coordinate position: these set of data were gotten from the offices of the telecommunications companies; MTN Nigeria and Zoom Mobile Nigeria, the data provided by the company includes place names of the mast, coordinates of the mast and in some cases range of the mast.

\subsubsection{Acquired Data}

This refers to the set of data used for the project that were obtained for use through different data acquisition methods, these includes;

- Spot heights data of Lagos state:

Given the contour map data that was available from the state surveyor generals office of Lagos we found that about $73 \%$ percent of Lagos was not covered, this posed a very big setback and alternative measures were researched to get an alternative. After we made our research we found that the best way to go about it was to develop our own contour maps for Lagos from spot heights, for this we needed a current and accurate means of getting the spot heights for the purpose of the project, (Moore, Pritsky, Rigg and Southwick, 2002).

Eventually we decided to use the Google map software to generate spot heights. A KMZ file was imported into Google earth software to demarcate the Lagos state boundary then a mesh of lines was designed in the Google earth interface using the polyline tool.

The corresponding elevation were written and tabulated against their corresponding $\mathrm{x}$ and $\mathrm{y}$ coordinates values, this was done using the Microsoft Excel spreadsheet software. The elevation values gotten from Google earth software is the corresponding Ellipsoidal height of each point as viewed by the satellite referred to the WGS 84 Ellipsoid. It was acquired directly in meters.

- Point of interest:

The coordinates of the point of interests (Service offices, Head offices), were gatherd using an hand held GPS, we visited the sites and took set pf readings at each location, averaged the readings for better accuracy and precision.

\subsubsection{Data Storage}

The data gathered were stored away using various types of storage devices which includes

- CD/DVD ROMs

- Flash drives

- Eternal/internal hard drives.

\subsubsection{Data Manipulation}

The data manipulation process can be distributed into the following stages:

1. Contour Creation From Spot heights

2. DEM creation from Contours

3. Rendering of DEM in 3 Dimensional model

4. Mast Data processing

5. Draping of Processed data to 3 dimensional DEM plane

\subsubsection{Contour Creation from Spot Heights}

After the process of acquiring the spot height data as explained in section 2.2.1.2 above, we went on ahead to create a contour profile, the software used for this process is the "GLODEN SURFER 8.0" plotting software the process is as stated below:

- Importing of the numeric data to the SURFER WORKSHEET environment

From the file menu of the of the software interface select the new command and the worksheet sub command this brings out a new worksheet pane in the interface, from this new pane the import subcommand of the file command is used to import the worksheet that was already in the Excel format (.xls format). After this is don the worksheet is then saved in the dat file format of the SURFER software with commas used as the delimiter option.

- Gridding the converted data

After the worksheet has been saved a new plot area was opened by selecting the new plot sheet command from the file menu, in the new plot sheet view the data sub command of the Grid menu was used to grid the data from the saved worksheet, the Kirgin interpolation spread method was used for the gridding process. 
- Plotting contour from the grid data

After the grid data had been created the contour profile was plotted using the new contour map command of the data menu, surface profiles and wireframes were also created using their corresponding commands under the data menu.

- Exporting data to .dxf

After the contour profiles were drawn, the contour was exported using the contour data export tool under the map menu, this is to enable integration into ArcGIS for further processing.

\subsubsection{DEM Creation from Contours}

Following the creation of contour in DXF format using the SURFER software, the next step was to convert the contour data into DEM MODEL using the ArcGIS desktop software, the process of conversion can be explained as follows:

- Input and conversion of contour model from DXF to Shapefile Format

The contour profile designed in the SURFER software was imported into ArcGIS using the add data command, this put the data in the ArcGIS workspace in an un-editable mode. The contour was then exported into a shapefile format which is editable, using the Export data command in the layer dropdown menu.

- Conversion of Shapefile feature to TIN (triangulation interpolation network).

After the creation of the shapefile the next step was to create a TIN file from the contour, a TIN file is a file format that the ArcGIS desktop software uses to house DEM 3 dimensional data. This infers that the creation of a TIN file is equivalent to the creation of a DEM.

The main tool used in the process is the 3D Analyst tool, this tool is responsible for any 3 dimensional process to be done in ArcGIS. After activating the 3D analyst tool using the Extension command under the tools menu bar, the shapefile was then converted o the 3D analyst tab using the "Create/modify TIN from Features" command on the 3D analyst task pane.

\subsubsection{Rendering of DEM in 3 Dimensional Model}

The ArcMap software interface was mainly tailored towards 2 dimensional representation and analysis. Hence, the reason why the DEM had to be rendered in ArcScene software interface which is made especially for 3 dimensional representation and analysis. The following steps explain the process of rendering in ArcScene;

- $\quad$ TIN importation and representation

The Add data command in ArcScene software interface was used to import the 3D TIN model created as explained above in section 3.3.2.3, after this was done the necessary parameters for displaying the model was set using the layers properties settings in the drop down bar menu of the layer. For the representation in 3D to be effectively viewed, an exaggeration had to be introduced. This is to enable the extruding differences in the modelled height to be visible in the ArcScene data environment. The value used for the exaggeration to the most reasonable and feasible view was 30 metres over the current coordinate system used which is WGS84 ellipsoid, (Petkovic, Djordjevic - Kajan, Stojanovic and Stoimenov, 2008).

\section{- Modelling Completion}

After the extrusion had been achieved using the exaggeration of the height, other relevant editing's were done to the TIN model to improve the quality and speed of the rendering in 3D view. These settings include the 3D characteristics when viewing in animated mode and the refresh rate of the models in view mode. These settings are essential for the smooth running of the model in ArcScene.

\subsubsection{Mast Data Processing}

The mast data that was gotten from the mobile operators got to us in an almost unusable format, certain editing and adjustments had to be done to make this data usable in ArcGIS. The following steps below highlights the process of editing and processing this data.

- Standardization and Conversion 
The data that came from both operators were in different coordinate systems, so it was essential for all the data to be brought to bear on the same units for correlation purposes. Eg. The data that came to us in geographic coordinate system had to be converted to rectangular coordinate system. This was done with the aid of standard conversion software specifically designed for spatial precision. The software used was Franson Coordinate Converter. This software takes into consideration the spatial discrepancies that come with conversion from one system to another and calculates for compensation accordingly.

\section{- Plotting \& Representation}

After the standardization process as explained above, the data was finally inputed into ArcGIS software environment by running the $\mathrm{X} / \mathrm{Y}$ plot script from the existing spreadsheet file where the data was stored. This converts the data into a temporal graphical representation called an event, this event is then exported into a shapefile format for actual storage and for later processing.

- Joining and correlation of mast data

After the data had been plotted and adequately represented we had to find a field of correlation between the two operators in order to allow for joint analysis i.e. the combining of the two dat sets into one shapefile. The tool used for this is called the join tool which can be found in the dropdown menu of the layers properties. There are two major types of joins that can be achieved which are has stated;

- Joining attributes from tables: this as to do with the connection of data from an external table that does not have a spatial representation in the ArcGIS environment

- Joining data from layer based on spatial location: this is the opposite of the method stated above, it entails the joining data form one spatially re[resented feature to another herby creating another set of spatially referenced features. This was the method used for the project

- Symbology \& Classification

This is a very important part of data processing that cannot be over emphasized, this is where the spatial data that have been graphically represented will be distributed and classified into their respective and various classes, at this point, the graphical view will be re-adjusted to fit the new classified representation. In the drop down menu of the shapefile layers, the symbology can be found in the properties menu. In the symbology tab, the view settings can be reviewed using the attribute data attached to the shapefile, this settings includes; icon representation; size; colour; and general customizations.

- Symbology Customization (Custom Icon)

For the purpose of the $3 \mathrm{D}$ viewing, custom icons had to be built in order to adequately portray a real life simulation of what the mast look like on ground. Autodesk 3Ds Max was used to customize the mast icons, proBoolean tools was used to reform and readjust basic conical wire frames in order to represent a mast shape interlock. The final rendering was made realistic by the addition of materials to give it a realistic finish. After the creation of the custom icons, it was imported into the database of ArcGIS icons using the style manager command under the tools menu bar. The icons was imported in .3ds format which was edited in order to place in its correct position in the cartesian plane, also the relative size was set to give it a proportional viewing in ArcScene.

\section{- Spatial Correlation}

After the processed stated above has been carried out, it is essential to analyse the graphical output to check for redundant representations or clashing symbologies. This is just a check to make sure that every later is well represented and in no way over shadowed by the symbolisms, colourings and size of other layers.

The following figures are shown in the appendices: The Administrative map of Lagos (Figure 2.1); The Complete Wireframe for Mast ((Figure 2.2); and the Complete Icon Representation in 3D (Figure 2.3).

\subsubsection{Information Presentation}

This involves the presentation of the result obtained after the analysis and processing have been carried out on the data; the obtained information is represented as Maps and Charts.

The Lagos Administrative Map Figures for the various queries are listed below and shown in the appendices.

Figure 2.1: $\quad$ The Lagos Administrative Map

Figure 2.2: $\quad$ Complete Wireframe for Mast

Figure 2.3: Complete Icon Representation in 3D

\section{Result and Analysis}

\subsection{Results}


The results was obtained and implemented through the analysis of information. The majority of information is spatial and can be mapped. Once information is mapped and attribute data is linked to the map, analysis of mast distribution and telecommunication management by the service distributors can begin. Using GIS in network monitoring is known to reduce the stress of the quality-monitoring engineer thereby increasing productivity. The results obtained from this project are listed below;

- Enhance response time to network issues. It simplifies the identification and resolution of network and service performance issues, resulting in maximized network performance, lower capital equipment costs and enhanced service

- Accelerate deployment and support of new technologies and services. It allows key knowledge users to capture and embed technical expertise and best-practice processes for rapid roll-out and support of new services

- Enhance understanding of customer and network behaviour. Spatial network monitoring tools could help evaluate the impact of voice service on radio network resources to better determine the requirements for future network expansion and the addition of new services.

- Lower network costs. It reduces operational expenses by minimizing the time and expertise required to perform common network analysis tasks; reduce capital expenditures by taking advantage of support for all commonly used hardware systems, legacy and future.

- And the possible unification of Control station which leads to optimization of services and resources.

\subsection{Query Building}

Structured Query Language (SQL) is a standard computer language for accessing and managing databases. SQL expressions are used in many parts of ArcGIS and its extensions to define a subset of data on which to perform some operation. You use it in ArcMap to select features with the Select by Attributes dialog box or with the Query Builder dialog box to set a layer definition query. You use it in geo-processing to define a subset of features or records to perform an operation on. You also use SQL to select features programmatically.

\subsubsection{Query Analysis}

The following query analysis were carried out for better appreciation of the facts on ground, this helps with the understanding and in turn provides solutions to problems.

The Figures for the various queries are listed below and shown in the appendices.

Figure 3.1: $\quad$ Selection showing all the Existing Zoom Mobile Masts

Figure 3.2: $\quad$ Selection showing all the Existing MTN Mobile Masts

Figure 3.3: $\quad$ Selection showing all the Existing MTN Mobile Offices

Figure 3.4: $\quad$ Selection showing all the Existing Zoom Mobile Offices

Figure 3.5: $\quad$ Selection showing the Proposed joint Masts Distribution Across Lagos.

Figure 3.6: Selection showing the Local Government Areas by Adult Population

\subsection{Buffering}

Proximity is another of the most basic GIS questions, such as:

- How close is this well to a landfill?

- Do any roads pass within 1000 meters of a stream?

- What is the distance between two locations?

- What is the nearest or farthest feature from something?

- What is the distance between each feature in a layer and the features in another layer?

- What is the shortest street network route from some location to another?

Proximity tools can be divided into two categories depending on the type of input the tool accepts: features or raster's. The feature-based tools vary in the types of output they produce. For example, the Buffer tool outputs polygon features which can then be used as input to overlay tools. The Near tool adds a distance measurement attribute to the input features, while the Select Layer By Location tool creates a selection set. The raster-based Euclidean distance tools measure distances from the center of source cells to the center of destination cells. The raster-based cost-distance tools accumulate the cost of each cell traversed between sources and destinations.

\subsubsection{Buffering Analysis}

Buffering analysis is a very important aspect of this project; this is because the effective service distribution is taken into account, the following buffers shows an essential part of the whole analysis which will serve as a basis for the corrections and suggestions made in the following chapter.

\subsection{Combined Analysis}


This is where both types of the above elaborated analysis methods are combined i.e. buffering and query analysis being used together to get a certain result.

The Figures for the various buffers and queries are listed below and shown in the appendices.

Figure 3.7: A Buffer of $1.25 \mathrm{Km}$ of Zoom Mobile Mast.

Figure 3.8: $\quad$ A Buffer of $2 \mathrm{Km}$ of MTN Mobile Mast.

Figure 3.9: $\quad$ A buffer of $10 \mathrm{Km}$ of proposed joint mast showing Signal Coverage

Figure 3.10: $\quad$ Multiple Query on Zoom Mobile Mast in Badagry LGA

Figure 3.11: Multiple Query on Number of Mast Against Population

3.5 Area and Statistical Analyses: Area and statistical analyses were also carried out. The results are shown in the under listed Figures.

Figure 3.12: Total Area of Administrative Regions in Lagos.

Figure 3.13: Bar Chart Representations of the Administrative Regions.

Figure 3.14: Calculation of Area of Zoom Mobile Mast Coverage of Buffer $1.25 \mathrm{Km}$

Figure 3.15: $\quad$ Bar Chart Representation of Zoom Mast Coverage Buffer of $1.25 \mathrm{Km}$

Figure 3.16: Calculation of Area of MTN Mobile Mast Coverage of Buffer $2 \mathrm{Km}$

Chart Representation of MTN Mast Coverage Buffer of $1.25 \mathrm{Km}$

Figure 3.17: Bar

Figure 3.18: $\quad$ Pie Chart of the Zoom Mobile Coverage

Figure 3.19: Pie Chart of the MTN Mobile Coverage

\section{Conclusion}

From the results obtained, it can be seen that the distribution of Zoom mobile mast in Lagos state is fewer relative to their competitor - MTN Nigeria.

The distribution pattern of these masts also shows that the service providers are more interested in areas where population density is high, commercial centres of the state and areas where income per head is high. This is appreciated in the number of masts sited by telecommunications provider in Ikeja, Ifelodun Ajeromi, Eti Osa, Lagos Mainland, Lagos Island, Surulere, Alimosho and Agege Local government areas. This can be seen in the maps available in the appendices.

It can also be deduce that the Lagos Island Local government area has quite a high number of masts relative to its land mass. This can be accrued to the high population and well developed vertical columns of the area which results into high traffic on the network and loss of coverage area due to hindrance in the line of sights of antennas.

In conclusion, the project has been able to provide graphically represented information to support in the area of:

- Network planning and management through the spatial representation of the available masts of telecommunications providers and the proposed location of joint masts on a DEM of the state to serve both telecommunications providers;

- Decision and operations support through the locations of their offices and equipment in the GIS which can be queried for easy and fast deployment of goods and services to customers.

- Marketing and customers services are also supported with the availability of demographic data in the GIS which will aid in the selection of hot spots where potential customers abound.

\section{Refrences}

[1] Burroughs P.A (1986): Principles of Geographical Information Systems. Principles and Applications, Longman, London.

[2] Chan, T. O. et al (1997): Data Structure and Application Issues in 3D Geographical Information Systems.

[3] Demers, M. M. (1997): Fundamentals of Geographic Information System.

[4] Egyedi, T. M (2001): "IPR Paralysis in Standardization: Is Regulatory Symmetry Desirable?" IEEE Communications Magazine, April 2001, pp. 108-144.

[5] Esri (2006): GIS for Telecommunication, ESRI Press, California USA

[6] Galati, R.S (2006): Geographic Information Systems Demystified. Artech House, London.

[7] Godin, L (2001): GIS in Telecommunications, ESRI Press, California USA

[8] Gunnar, H (1998): GSM Networks - Protocols, Terminology and Implementation, Artech House, London.

[9] Jones N.V (2005): Telecommunications Management. Colorado Reader, USA

[10] Moore S. M., Pritsky N.T., RiggS C. and Southwick P.V. (2002): Telecommunications: A Beginner's Guide, McGraw Hill, USA

[11] Petkovic M.S., Djordjevic - Kajan S., Stojanovic D.H., and Stoimenov L.V(2008): The Role of GIS in Telecommunication Network Maintenance. Computer Graphics and GIS Laboratory, University of Nis Beogradska, Yugoslavia.

[12] Petkovic, M. S. (2002): The Role of GIS in Telecommunication Network Maintenance

[13] Tarmo A (2003): Introduction to Telecommunications Network Engineering, Artech House, London.

\section{APPENDICES}




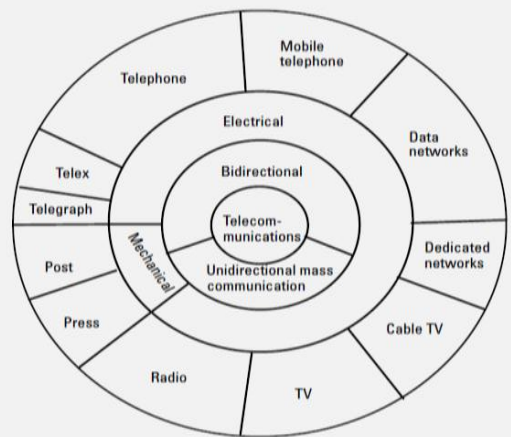

Figure 1.1 Telecommunications. Source: TARMO A (2003; Introduction to Telecommunications Network Engineering.

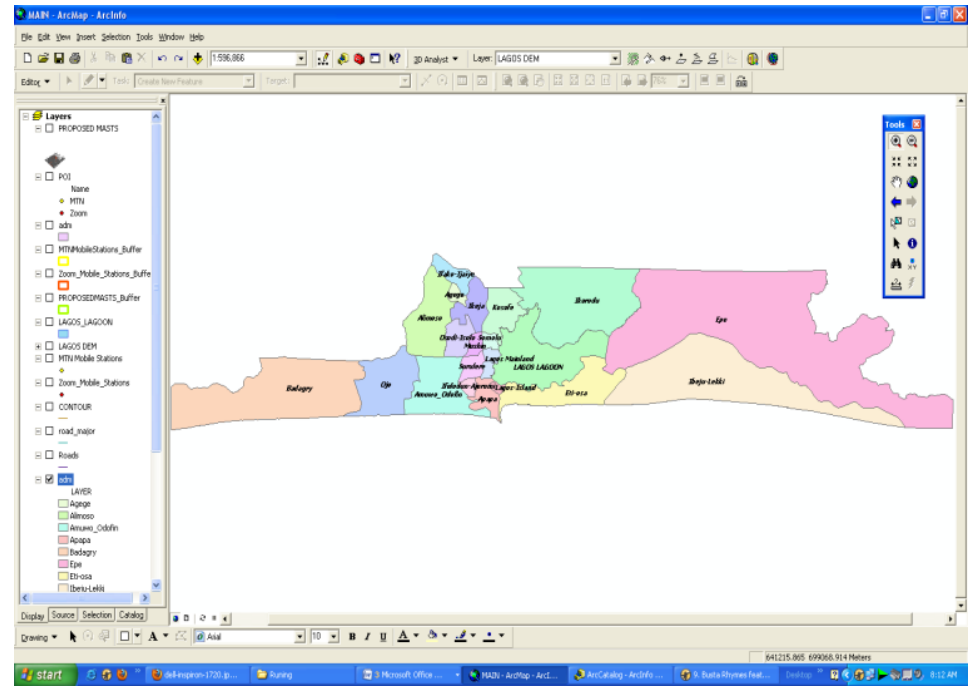

Fig 2.1 Lagos Administrative map

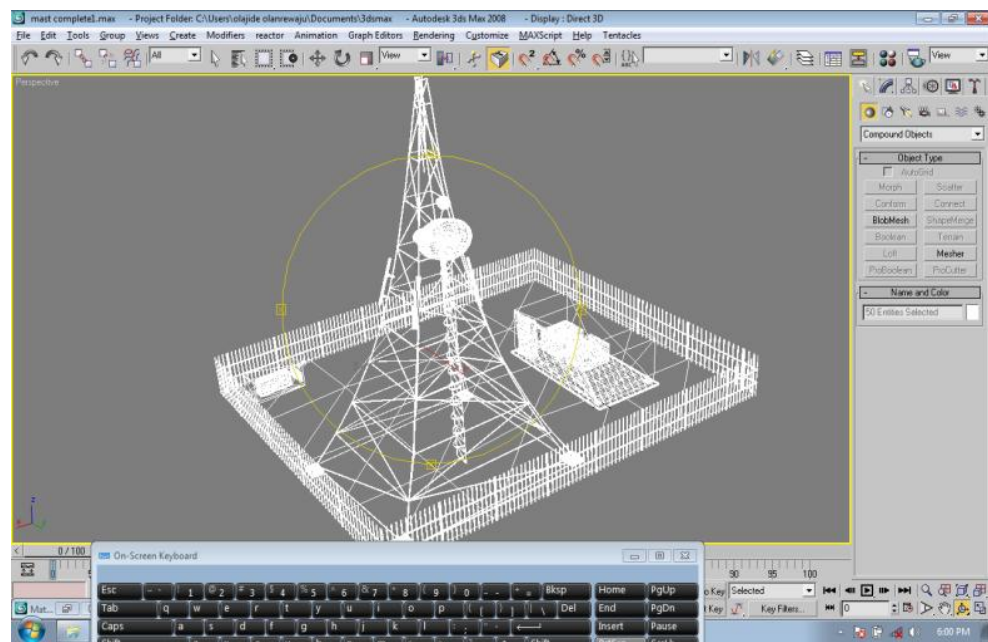

Fig 2.2 Complete wireframe for mast 


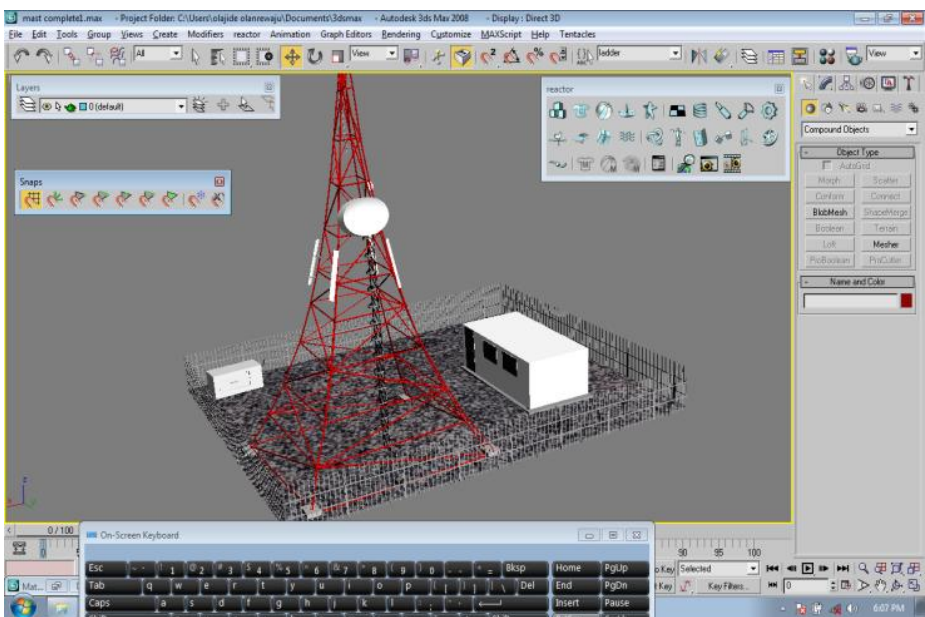

Fig 2.3 Complete Icon representation in 3D

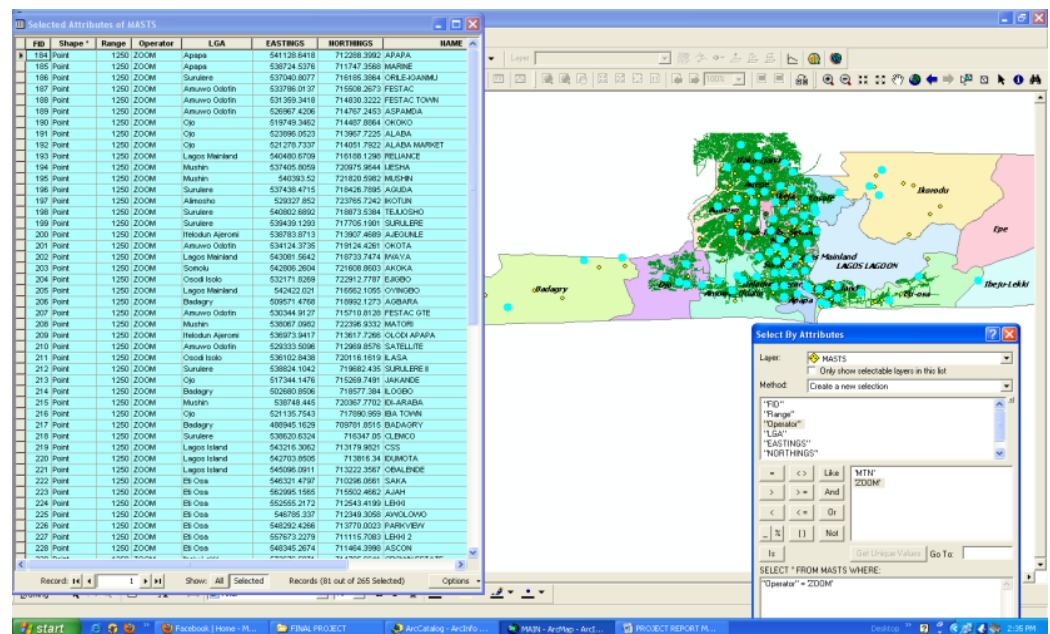

Fig 3.1 Selection showing all the existing zoom mobile masts

Query Syntax = "Operator" = 'ZOOM'

The figure above shows the total number of ZOOM mobile masts in Lagos. The total number being 81 of 265 masts with their corresponding attributes table all highlighted in blue as shown above.

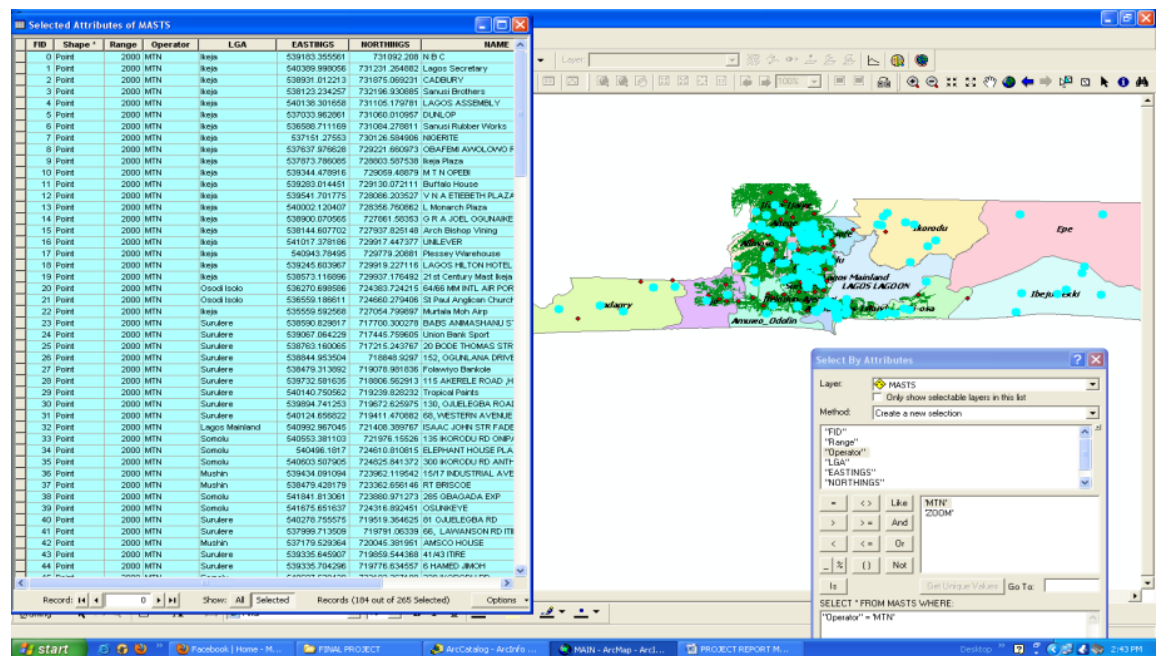

Fig 3.2 Selection showing all the existing MTN mobile masts

Query Syntax = "Operator" = 'MTN'

The figure above shows the total number of MTN mobile masts in Lagos. The total number being 184 of 265 masts with their corresponding attributes table all highlighted in blue as shown above. 


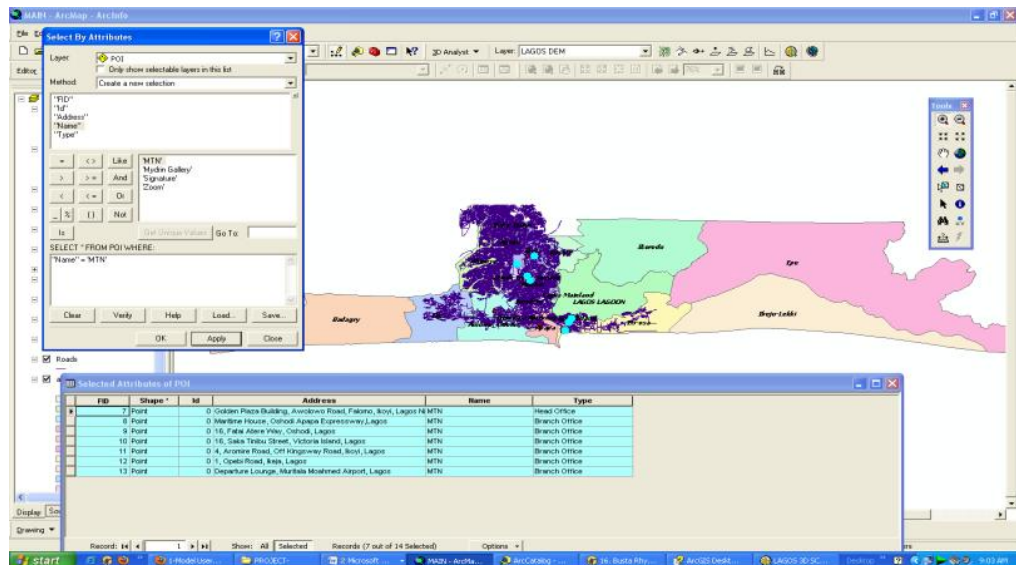

Fig 3.3 Selection showing all the existing MTN mobile Offices / service points

Query Syntax = "Name" = 'MTN'

The figure above shows the total number of MTN mobile offices in Lagos. The total number being 7 of 12 offices with their corresponding attributes table all highlighted in blue as shown above.

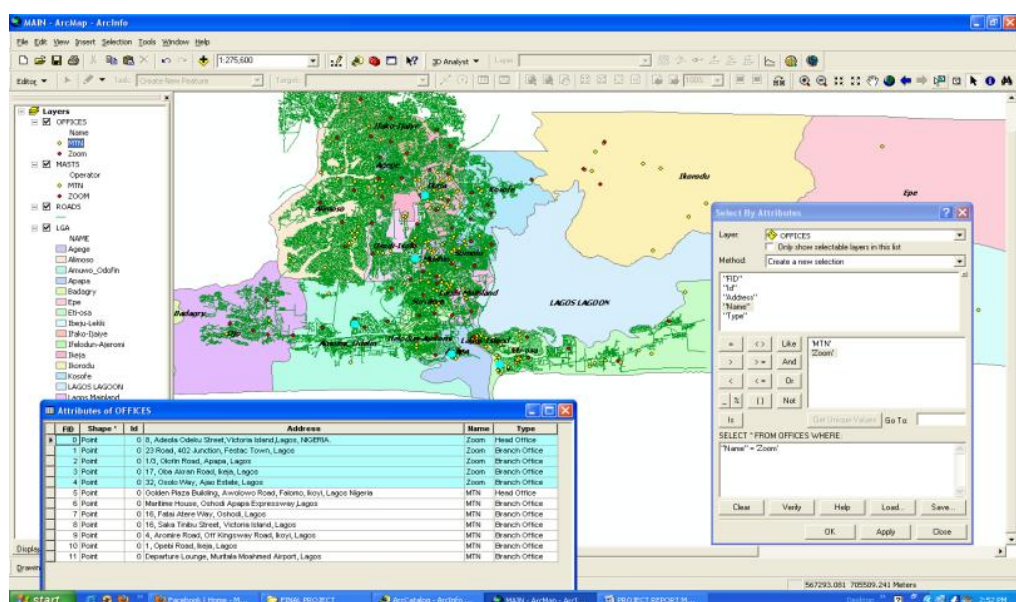

Fig 3.4 Selection showing all the existing Zoom mobile Offices / service points

Query Syntax = "Name" = 'Zoom'

The figure above shows the total number of ZOOM mobile offices in Lagos. The total number being 5 of 12 offices with their corresponding attributes table all highlighted in blue as shown above.

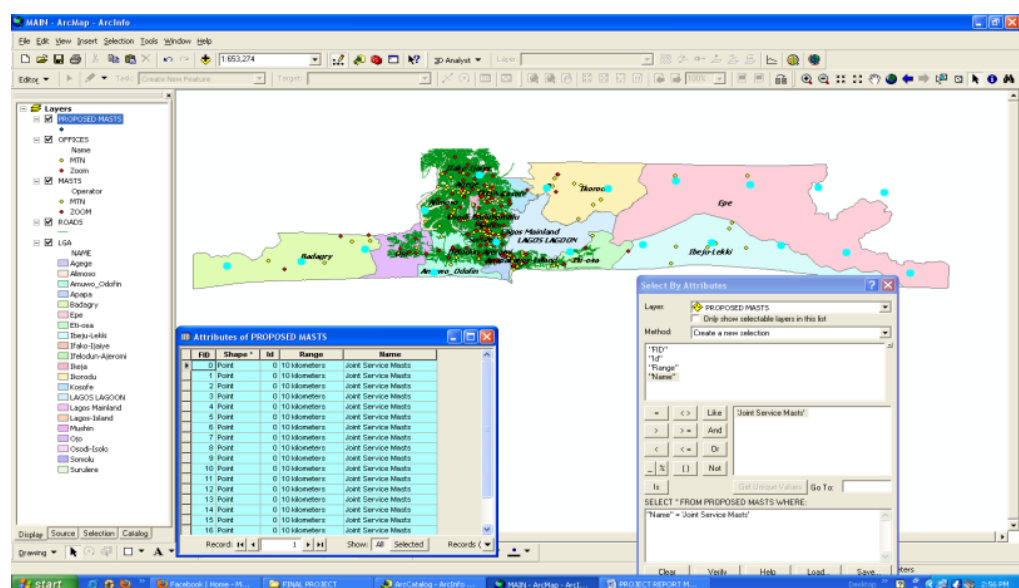

Fig 3.5 Query showing the proposed Joint Service mast's distribution across Lagos

Query Syntax = "Name" = 'Joint Service Masts'

The figure above shows the total number of proposed masts for Lagos. The total number being 19 masts with their corresponding attributes table all highlighted in blue as shown above 


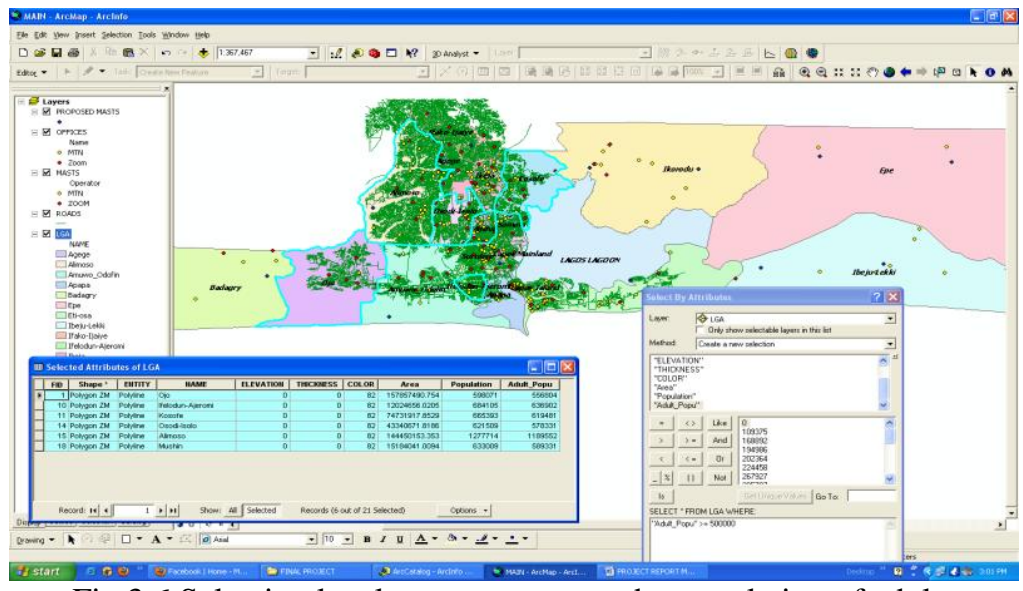

Fig 3.6 Selection local government area by population of adults

Query Syntax = "Adult_Popu" >=500000

The figure above shows the results of the query for local government areas with adult population of 500,000 and above, highlighted in blue along with the attribute tables

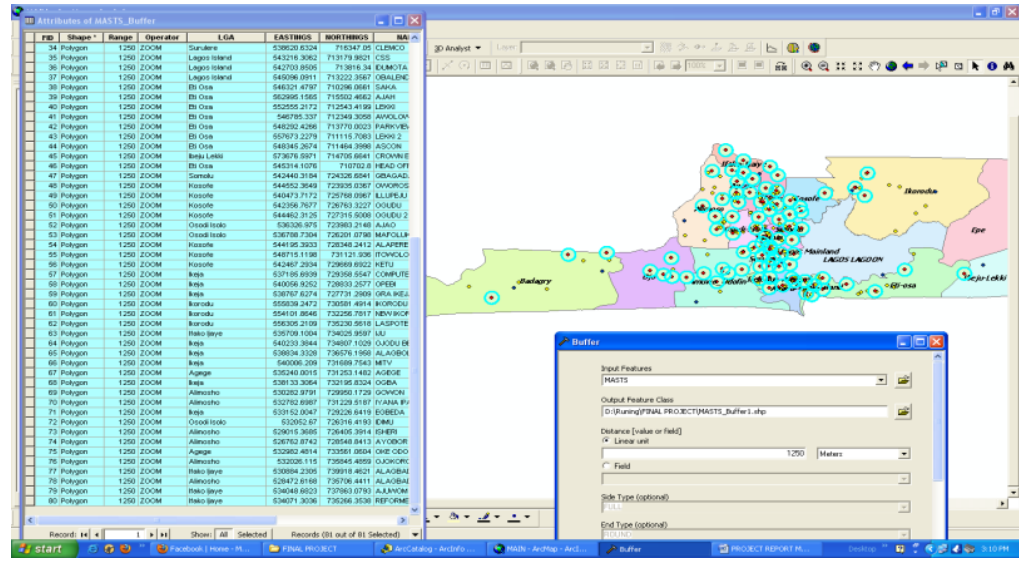

Fig 3.7 A Buffer of 1.25 kilometres of ZOOM mast showing signal coverage area.

The figure above shows the multiple buffer of 1.25 kilometre radius, which represents the service coverage area for ZOOM mobile masts in Lagos highlighted in blue along with their corresponding attribute table

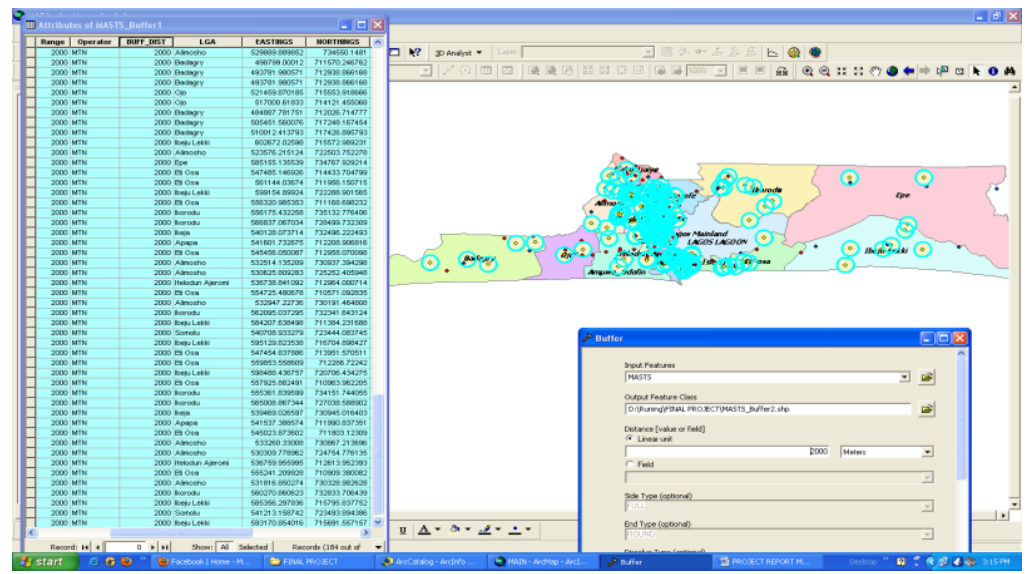

Fig 4.8 A Buffer of 2 kilometres of MTN mast showing signal coverage.

The figure above shows the multiple buffer of 2.0 kilometre radius, which represents the service coverage area for MTN mobile masts in Lagos highlighted in blue along with their corresponding attribute table 


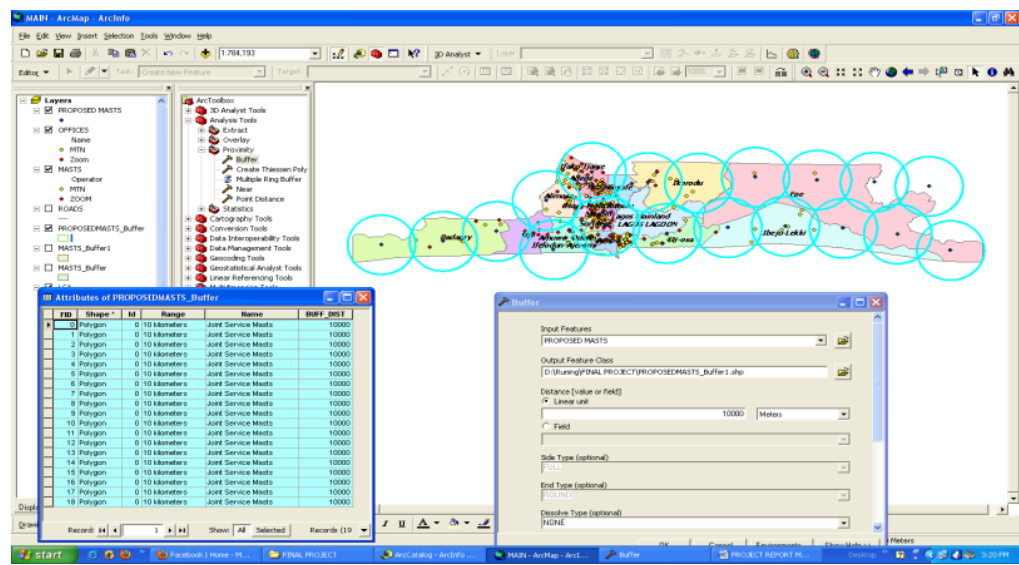

Fig 3.9 Buffer of 10 kilometres of joint mast Showing signal coverage.

The figure above shows the multiple buffer of 10 kilometre radius, which represents the service coverage area for the proposed mobile masts for Lagos highlighted in blue along with their corresponding attribute table

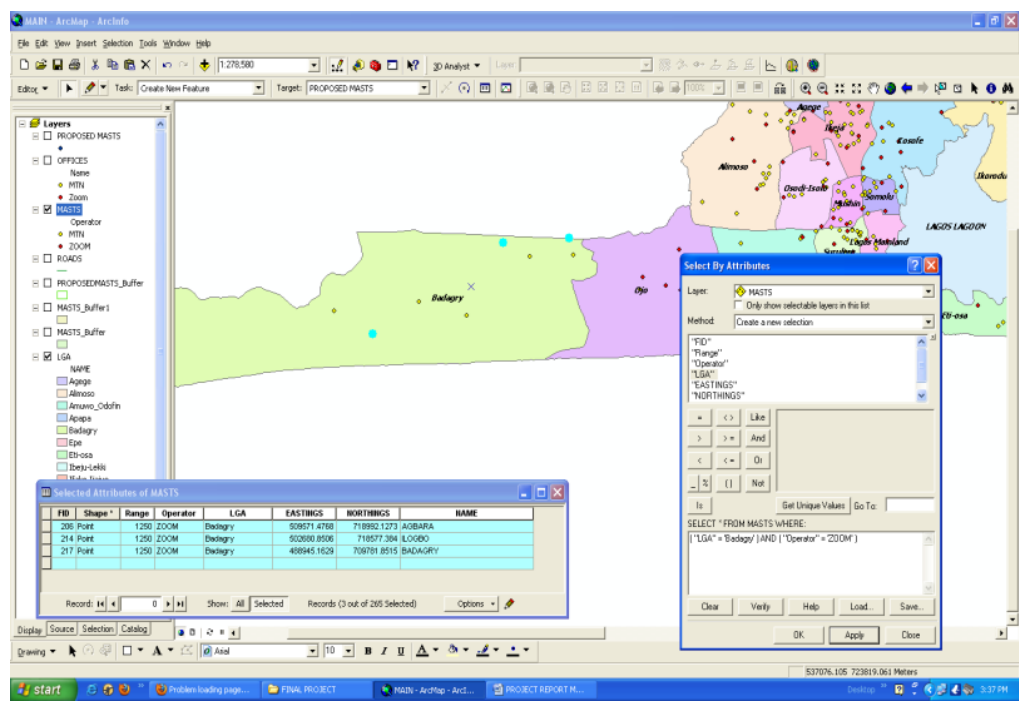

Fig 3.10 Multiple query of Badagry area for Zoom masts

Query Syntax = ("LGA" = 'Badagry') AND ("Operator" = 'ZOOM')

The figure above shows the multiple query analysis, which highlights in blue the ZOOM mobile masts that are located within Badagry local government area along with the attribute table

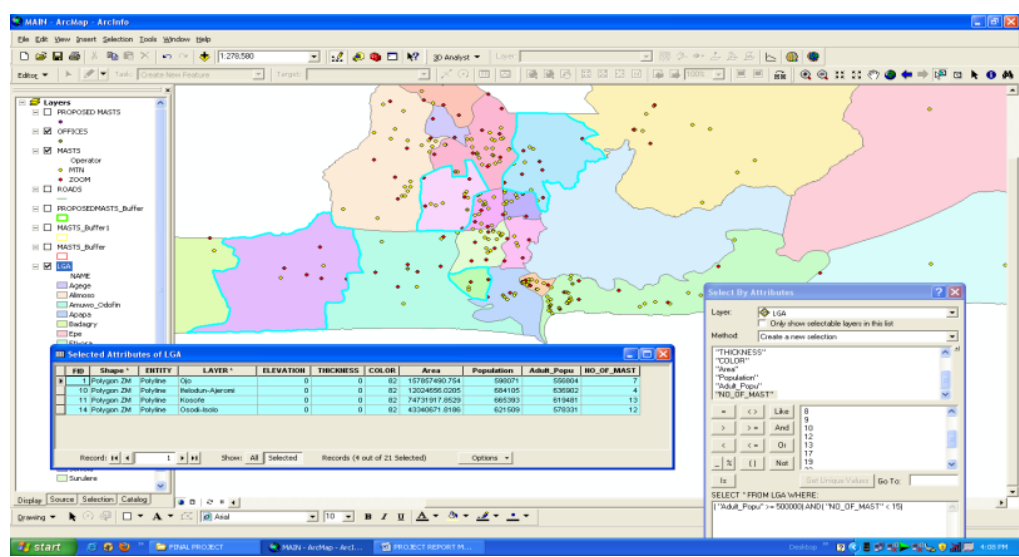

Fig 3.11 Multiple query of local governments for number of mast's against population

Query Syntax = ("Adult_Popu" >= 500000) AND( "NO_OF_MAST" < 15))

The figure above shows the multiple query analysis, which highlights in blue the local governments whose adult population is over 500,000 and have less than 15 masts servicing them along with their attribute table. 


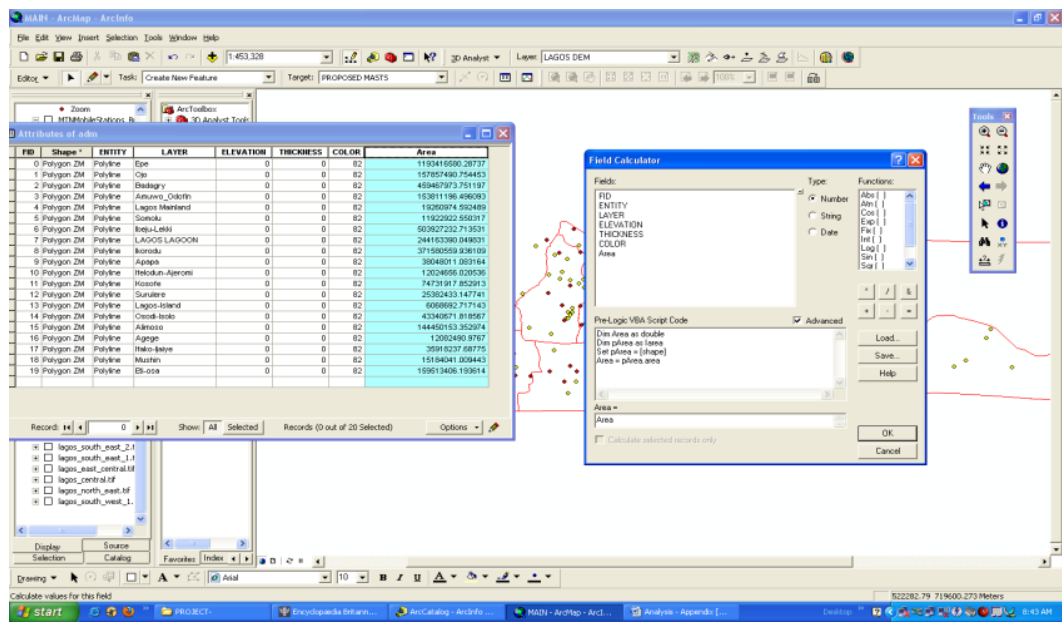

Fig 3.12 Calculation of total Area of Administrative regions in Lagos

Dim Area as double

Script Syntax =

Set pArea $=[$ shape $]$

Area $=$ pArea.area
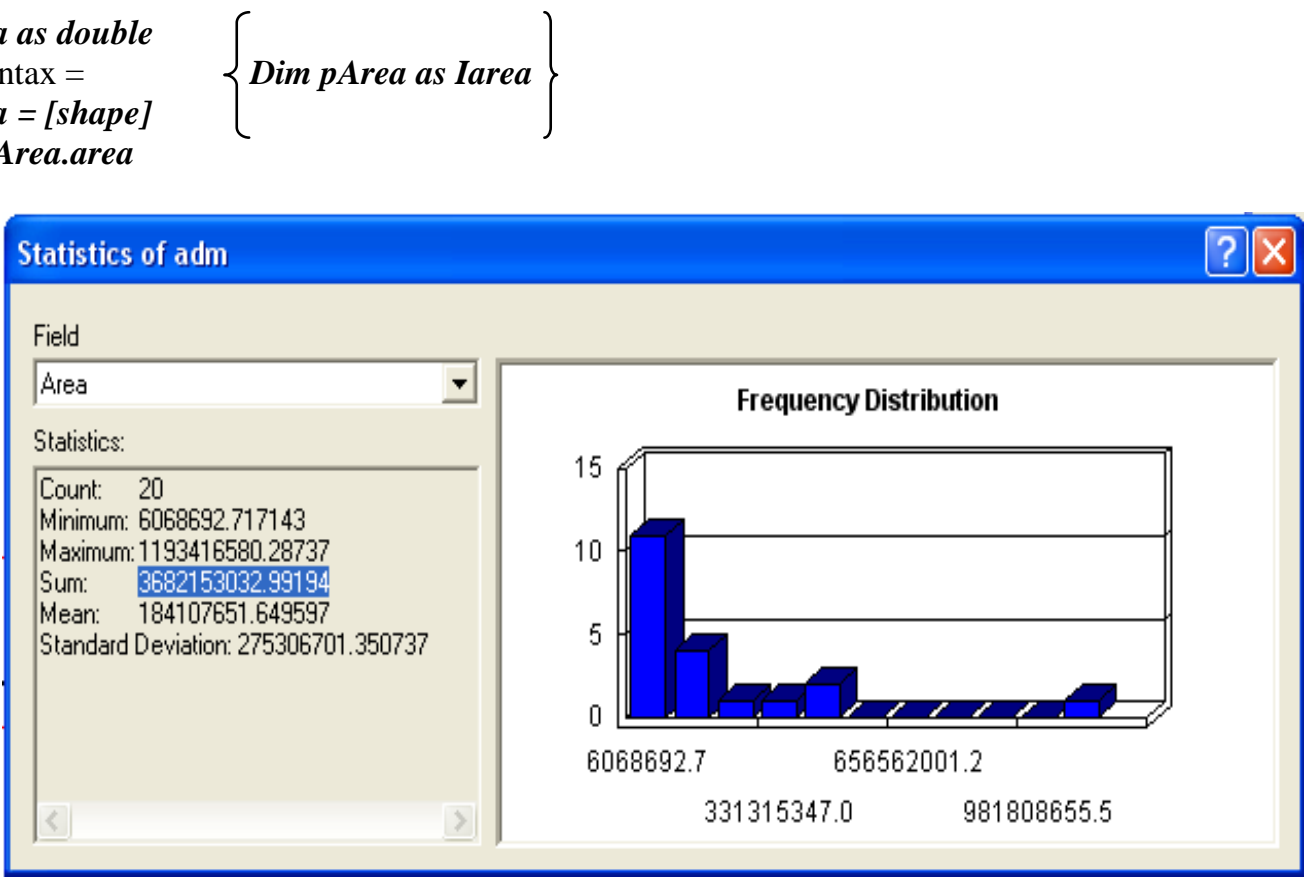

Fig 3.13 Bar chart representation of the Administrative region

The following statistical data were generated from the area calculation of the local government area's;

Count: 20

Minimum: $\quad \mathbf{6 0 6 8 6 9 2 . 7 1 7 1 4 3}$

Maximum: $\quad 1193416580.28737$

Sum: 3682153032.99194

Mean: 184107651.649597

Standard Deviation: $\quad 275306701.350737$ 


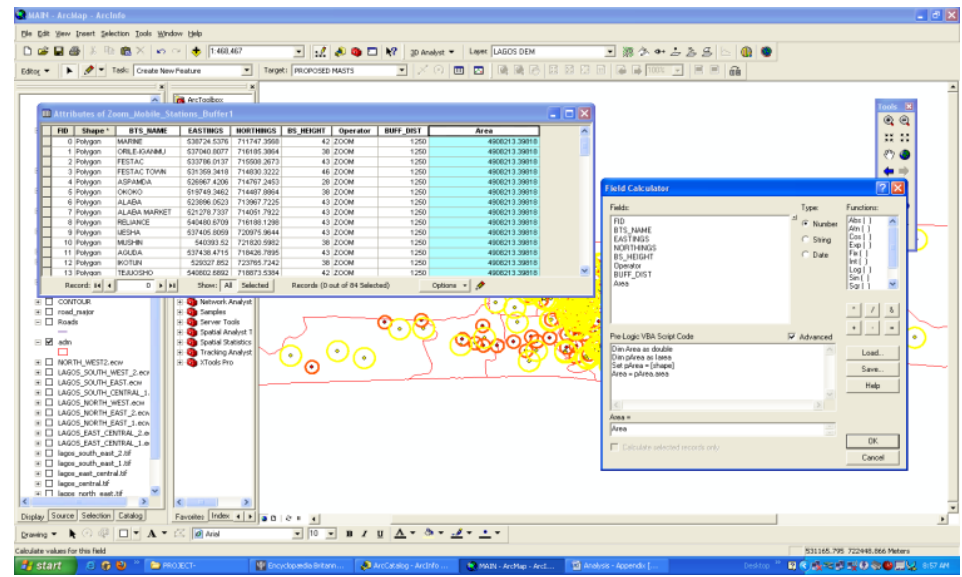

Dim Area as double Script Syntax = Set pArea $=[$ shape $]$ Area $=$ pArea. area

Fig 3.14 Calculation of total Area of Zoom mast Buffer for 1.25 kilometres
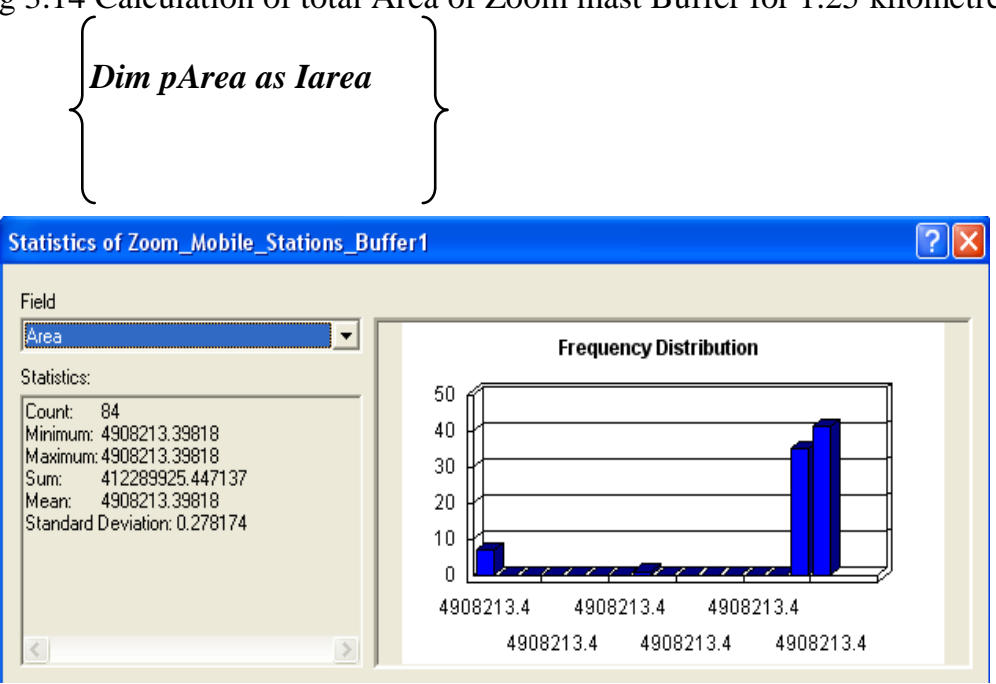

Fig 3.15 Bar chart representation of Zoom mast Buffer of 1.25 kilometres

The following statistical data were generated from the coverage area calculation of the ZOOM mobile service coverage buffer;

Count: 84

Minimum: $\quad 4908213.39818$

Maximum: $\quad 4908213.39818$

Sum: 412289925.447137

Mean: 4908213.39818

Standard Deviation:

0.278174

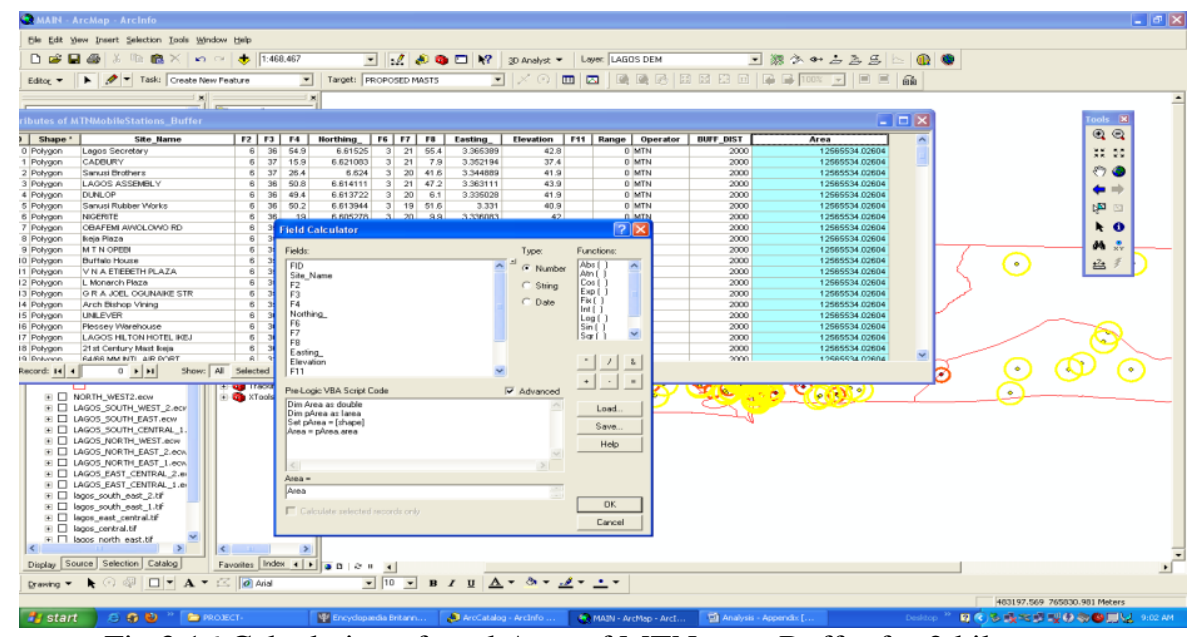

Fig 3.16 Calculation of total Area of MTN mast Buffer for 2 kilometres

\begin{tabular}{l|l} 
Dim Area as double & \\
\hline www.josrjournals.org & $73 \mid$ Page
\end{tabular}


Script Syntax = Set pArea $=[$ shape $]$

\section{Dim pArea as Iarea}

Area $=$ pArea. area

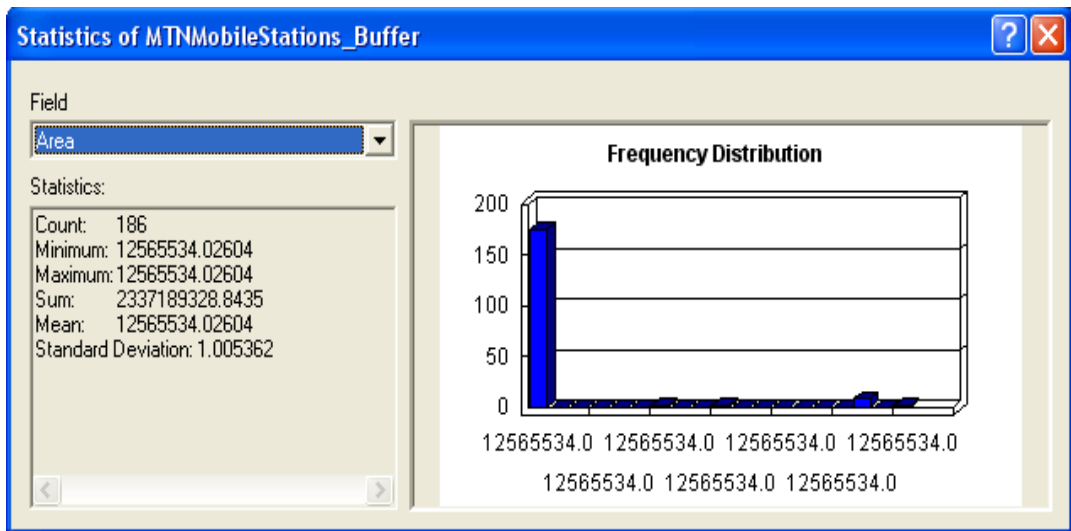

Fig 3.17 Bar chart representation of MTN mast Buffer of 2 kilometres

The following statistical data were generated from the coverage area calculation of the MTN mobile service coverage buffer;

Count: 186

Minimum: $\quad 12565534.02604$

Maximum: $\quad 12565534.02604$

Sum: $\quad 2337189328.8435$

Mean: 12565534.02604

Standard Deviation: $\quad 1.005362$

Percentage of coverage of Zoom network in relation to total administrative area

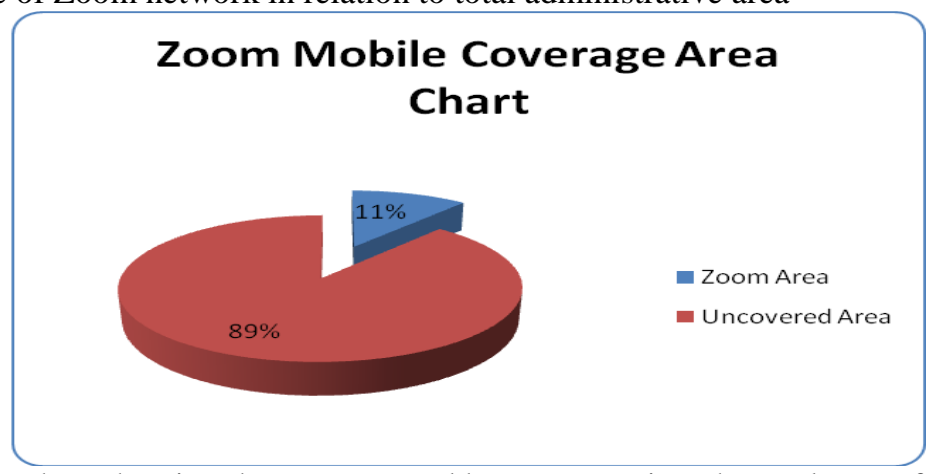

Fig 3.18 Pie chart showing the area covered by Zoom against the total area of Lagos state

$\frac{412289925.447137 \times}{3682153032.99194} \quad 100 \ldots \quad=\quad 11.196 \%$ of the total area is covered by Zoom

Percentage of coverage of MTN network in relation to total administrative area 


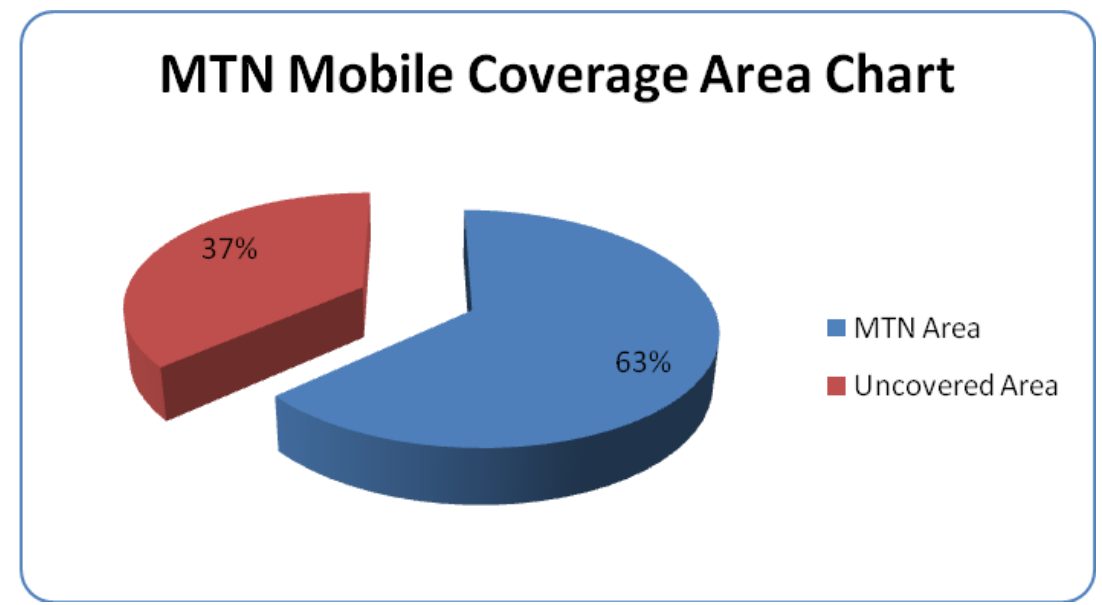

Fig 3.19 Pie chart showing the area covered by MTN against the total area of Lagos state

$\begin{array}{llll}2337189328.8435 & \times & 100 & =\end{array} \quad 63.473 \%$ of total area to be covered

Percentage of coverage of proposed joint Base station in relation to total administrative area

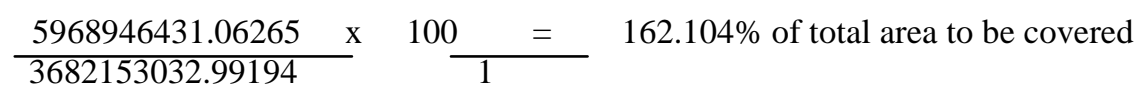

From the result above it can be deduced that the entire area of Lagos is effectively covered and even extends to other neighbouring states. 